\title{
Bağlanma ve Depresyon Arasındaki İlişkinin Çeşitli Değişkenler Açısından İncelenmesi: Teorik Bir Çalışma
}

\section{Examining the Relationship between Attachment and Depression in Terms of Various Variables: A Theoretical Study}

Zeynep Set ${ }^{1} \mathbb{D}$

\begin{abstract}
$\ddot{0} z$
Heinz Kohut tarafından geliştirilen kendilik psikolojisi yaklaşımı, günümüzde en temel psikanalitik teorilerden biri olarak görülmektedir. Kohut'un kendilik kuramı ve Bowlby'nin bağlanma kuramı, bakım verenler ile kurulan ilişkinin önemi ve bunun sağlıklı bir kendilik duygusunun gelişimi ve yetişkinlik döneminde kurulacak ilişkiler üzerinde etkisi olacağı üzerinde durmaktadır. Bu araştırmada, kendilik psikolojisi içerisinde yer alan kendilik nesnesi kavramı ve bağlanma kuramının detaylı bir şekilde açıklanması hedeflenmiştir. Bu bağlamda kendilik nesnesi ve bağlanma boyutlarının etkilerini incelemek için bağlanma ve kendilik nesnesi ile depresyon, anksiyete ve öznel iyi oluş ilişkisi ve bu ilişkilerde duygu düzenlemenin olası aracı etkisine dair alanyazın incelenmiştir. Illeride yapıllacak araştırmalar için önerilerde bulunulmuştur.
\end{abstract}

Anahtar sözcükler: Bağlanma, kendilik psikolojisi, psikolojik semptomlar, öznel iyi oluş, duygu düzenleme

\section{Abstract}

Self-psychology concept, developed by Heinz Kohut, is now seen as one of the most fundamental psychoanalytic theories. Kohut's theory of self psychology and Bowlby's attachment theory emphasizes the importance of early care giving relationship and how this has a profound effect on the development of a healthy sense of self and relationship in adulthood. In this study, it is aimed to explain the concept of self-object in self-psychology and attachment theory in detail. In this context, in order to examine the effects of self-object and attachment dimensions, the literature findings related to attachment and self-object with depression, anxiety and subjective well-being and the possible mediator effect of emotion regulation in these relationships were investigated. Suggestions were made for future research.

Keywords: Attachment, self-object, psyhchological symptoms, subjective well-being, emotion regulation

${ }^{1}$ Tekirdağ Namık Kemal Üniversitesi, Tekirdağ, Türkiye

$凶$ Zeynep Set, Tekirdağ Namık Kemal Üniversitesi, Psikoloji Bölümü, Tekirdağ, Türkiye zset@nku.edu.tr |0000-0002-0223-683X

Geliş tarihi/Received: 01.04.2020 | Kabul tarihi/Accepted: 06.05.2020 |Çevrimiçi yayın/Published online: 01.12.2020 
HEINZ KOHUT $(1971,1977)$ tarafından geliştirilen kendilik psikolojisi, günümüzde en temel psikanalitik teorilerden biri olarak görülmektedir (Mollon 2001, Strozier 2001). Hem kişilik gelişimine yönelik açıklama sunması, hem de psikopatoloji yapılanması ve terapötik sürece yönelik bütüncül bir yaklaşım içermesi sebebi ile kapsamlı bir teoridir. Kohut (1971) kendiliği, kişinin kendisiyle ilgili imgeler bütünü ve kendini algılayış biçimi şeklinde tanımlamıştır. Kohut'a göre (1971, 1977, 1984) kendilik (öznel deneyimi düzenleyen bir süreç ya da sistem olarak görülür) bir kişinin psikolojik varlığının özüdür, kendine ve dünyaya karşı duyumlar, duygular, düşünceler ve tutumlardan oluşur. Kohut kendiliği, olgun ve sağlıklı bir kişiliğin gelişiminin yanı sıra kişilik bozuklarının oluşumunu açıklayan psikolojik bir güç olarak görmektedir.

Kohut, cinsel ve saldırgan içgüdülerin önemini azaltarak Freud'un teorisini önemli ölçüde değiştirmesine rağmen, Freud'u (1933) takip ederek bireyleri içgüdülerin "nesnesi” olarak adlandırmıştır. Kendilik nesnesi, bireyin erken dönemde benliğinin gelişiminde ve bütünlüğ̈nü sağlamada rol oynayan kişiyi (bakım vereni) temsil etmektedir. Kendilik nesneleri, kendiliğin bir parçası olarak algılanan nesnelerdir. Teorinin temelinde, bireyin öznel deneyimini çeşitli gelişimsel ihtiyaçlarla ilişkili olarak düzenleyen, zihinsel bir sistem olarak kavramlaştırılmış olan kendilik yatmaktadır (Wolf 1988). Kohut (1971) bu ihtiyaçları "kendilik nesnesi ihtiyaçları" olarak adlandırmıştır, çünkü kendiliğin sürdürülmesi ile ilişkilidir ve bireyin hayatındaki dış figürler tarafından karşılanmaktadır (veya karşılanmamaktadır). Kohut $(1977,1984)$ erken bakım deneyimlerinde kritik gelişimsel ihtiyaçların karşılanmasının uyumlu bir kendilik duygusu gelişimini teşvik etmede önemli bir rol oynadığını vurgulamaktadır. Kohut'a göre, gelişmekte olan kendiliği etkileyen üç ana kendilik nesnesi ihtiyacı vardır. Bunlar aynalanma, idealleştirme ve ikizliktir. Aynalanma ihtiyacı, kişinin nitelikleri ve başarıları için takdir edilmesini içerir. Kohut (1971) çocukların kendilerine hayran olan, ilerlemelerini kutlayan ve başarılarını alkışlayan bir bakım verene ihtiyaç duyduklarını öne sürmüştür. Aynalanma ihtiyacının, bebeğin ilk yıllarda kendiliğine odaklanarak kusursuz ve iyi özellikleri kendisine ait görmesi, kötü ve kusurlu özellikleri ise diğlerine ait gördüğü "büyüklenmeci kendilik" ya da "narsistik kendilik" yapısı ile ilişkili olduğunu ileri sürmüştür. Bu kendilik nesnesi ihtiyacını tatmin etmek, başkaları tarafından değerlenilmeyi ve kişinin niteliklerinden ve başarılarından gurur duyulmasını içerir; bu da Kohut'un sağlıklı bir "büyüklenme" duygusu olarak gördüğü kavrama katkıda bulunur. Aynalanma ihtiyacından farklı olarak idealleştirici kendilik nesnesi ihtiyaçları, güvenli bir bağlanma figürüne ihtiyaç duymaya benzer bir şekilde, stres zamanlarında idealize edilmiş bir başkasına güvenme ve birlik olma arzusundan kaynaklanır. İdealleştirme ihtiyacı ise, kusursuzluğun dışsal bir figüre yansıtılması durumunu içerir ve bu figürün genellikle her şeyi bildiğine ve sınırsız gücü olduğuna inanılan ebeveyn figürü olduğuna inanılmaktadır. Çocukların hayran oldukları bir veya daha fazla ideal ebeveyn figürünün bulunması ve kendileri ile ilişkili oldukları duygusu gelişimlerinde daha güvenli hissetmelerini sağlamakta ve yüksek ama gerçekçi hedefler koyma yeteneklerini güçlendirmektedir. İkizlik nesnesi ihtiyacı ise, başkalarına benzer hissetme ve onlarla ilişkide bulunma ihtiyacıdır. Karşılanan ikizlik kendilik nesnesi ihtiyaçları, daha büyük bir gruba yakınlığa, aidiyet duygularına 
işaret eder, bağlantı hissini kolaylaştırır ve topluluk kurallarının benimsenmesini, empati ve bağlantılılık duygusunun gelişmesini arttırır (Kohut 1971).

Bağlanma teorisi ise ilk olarak, bakım veren ve çocuk arasındaki duygusal bağı tanımlamak için Bowlby, Ainsworth ve arkadaşları tarafindan öne sürülmüştür (Bowlby 1969, Ainsworth ve ark. 1978). Bağlanma teorisine göre (Bowlby 1969), bağlanma sistemi bebeklik döneminde korunma ve güvenlik duygusunu sağlamak amacıyla hem bebeğin hem de bakım verenin davranışlarını düzenlemektedir. İhtiyaçları tutarlı bir şekilde karşılanan çocuklar güvenli bağlanma modelleri geliştirirken, reddedilen çocuklar, ihtiyaçlarının karşılanacağına dair endişe ve şüphe duyduklarından güvensiz bağlanma modelleri geliştirirler. Güvenli bağlanmış bireyler için, temel bağlanma figürlerinin mevcudiyeti ve sıkıntıyı hafifletme kabiliyetleri ile ilgili olumlu düşünceler ve kendilerine bakım verilmesine değer olduklarına dair inançlar gelişir (Bowlby 1980). Bowlby (1988) güvenli bağlanmayı duygusal dengeyi korumak, olumlu bir kendilik imajı geliştirmek ve tatmin edici yakın ilişkiler kurmak için gerekli görmektedir. Ayrıca, güvenli bağlanmanın, kişinin güvenli bir ortamda hedeflere ulaşabileceği ve gerektiğinde destek alabileceği duygusunu güçlendirdiğinden kişinin kendini gerçekleştirmesine yardımcı olduğunu söyler (Bowlby 1988). Ainsworth ve ark. ise (1978) çocukların annelerinin mevcudiyeti, yokluğu ve geri dönüşü sırasındaki davranışlarına dayanarak üç tür bağlanma stili (güvenli, kaygılı, kaçınmacı) tanımlamıştır. Kaygılı bağlanmaya sahip bireyler, bakım verenleri tarafından ihtiyaçları tutarlı karşılanmadığı için diğerlerine karşı şüphe duyarlar ve ihtiyaç duyduklarında duyarlı olmayacaklarına dair bir endişe yaşarlar. Kaçınmacı bağlanmaya sahip bireyler ise, kendine güvenen, bağımsız ve duygusal mesafeyi koruyan kişileri içermektedir (Hazan ve Shaver 1987).

Her iki teori de, erken bakım verenler ile kurulan ilişkinin önemi ve bunun sağlıklı bir kendilik duygusunun gelişimi ve yetişkinlik döneminde kurulacak ilişkiler üzerinde etkisi olacağ1 üzerinde durmaktadır. Bu bağlamda kendilik nesnesi ve bağlanma boyutlarının etkilerini incelemek için bağlanma ve kendilik nesnesi ile depresyon, anksiyete ve öznel iyi oluş ilişkisi ve bu ilişkilerde duygu düzenlemenin olası aracı etkisine dair literatür bulguları araştırılmıştır.

\section{Kendilik nesnesi ve bağlanma arasındaki ilişki}

Kendilik nesnesi ihtiyaçları ve bağlanma boyutları arasındaki ilişkiyi inceleyen az sayıda çalışma olmasına karşın, bu iki boyutun ilişkili bulunması şaşırtıcı değildir (Banai ve ark. 2005, Lopez ve ark. 2013). Kohut'un kendilik kuram1 (Kohut 1984) ve Bowlby'nin (1969) bağlanma kuramı, erken bakım ilişkisini ve bunun sağlıklı bir kendilik duygusunun gelişimi üzerinde nasıl derin bir etkisi olduğunu vurgular (Schore 2002). Her iki teorisyen de bakım verenin çocuğun erken dönem ihtiyaçlarına yanıt verebilirliğinin çocuğun yetişkinlik dönemi özelliklerini ve yetişkinlikte kuracağı yakın ilişkileri etkileyeceğini öne sürmektedir. Kohut, bakım veren ile (aynalama, idealize etme ve ikizlik) ilişkiden gelişen üç kendilik nesnesi aktarımına odaklanmış olsa da, Bowlby bağlanma ilişkisinde, hiperaktivasyon ve deaktivasyon sonucunda gelişen otomatik duygu düzenleme stratejilerine odaklanmıştır. Bağlanma figürleri güvenilir bir şekilde ulaşılabilir ve destekleyici olmadığında güvenlik hissine ulaşılamaz, 
kendileri ve diğerleri ile ilgili olumsuz düşünceler oluşur ve hiperaktivasyon ve deakstivasyon olmak üzere ikincil duygu düzenleme stratejileri devreye girer. Hiperaktivasyon stratejileri, keşif sırasında bebeği kaygılı bırakan tutarsız ve güvenilmez bakım verenler tarafından oluşmaktadır. Hiperaktivasyon stratejileri, ruminasyon ve kaygıyı kullanarak (Cassidy 1994) bağlanma figülerinden yakınlık istemeyi içermektedir (Mikulincer ve ark. 2003). Kohut açıkça bu stratejilere değinmese de, karşılanmamı̧ kendilik nesnesi ihtiyaçlarını karşılama açlığı, bu ihtiyaçları karşılamayı amaçlayan stratejilerin hiperaktivasyonu olarak tanımlanabilir (Banai ve ark. 2005).

Deaktivasyonun ise duygusal ihmalden kaynaklandığı söylenmektedir (Mikulincer ve Shaver 2007). Yakınlık ihtiyacı karşılanmayan bebek, kendi kendine yetebilmeye çalı̧̧arak bakım verme ortamına uyum sağlamaya çalışır. Ainsworth ve arkadaşlarının (1978) kaçınmacı bağlanma tanımlaması deaktivasyon stratejilerini göstermektedir. Çocuk, bakım verenden ayrılma sırasında fizyolojik olarak sıkıntılı olsa da, bakım vereni ile tekrar bir araya geldiğinde onunla bağlantı kurmaktan kaçınılır. Deaktivasyon stratejileri diğerlerinden duygusal bir mesafe yaratmayı içerir (Mikulincer ve ark. 2003). Diğer stratejiler ise, sıkıntılı bilişlerin ve hatıraların bastırılmasını içerir (Shaver ve Mikulincer 2002). Deaktivasyon stratejileri savaş ya da kaç tepkilerini zamanla bastırarak utanç ve sıkıntıyı geçici olarak en aza indirir (Schore 2002).

Kohut (1971, 1977), kendilik nesnesi aktarımlarına odaklanmanın yanı sıra, kişiler arası ilişkilerin çocukluktan yetişkinliğe benlikte uyum duygusunu oluşturmadaki katkısını açıklamaya çalışmıştır. Bu bağlamda görüşleri Bowlby ve Ainsworth’un bağlanma teorisine benzerdir (Ainsworth ve ark. 1978, Bowlby 1980, 1982). Uyumlu bir benliğin gelişimi bir kişinin sıkıntılı durumu yönetmek istediğinde önemli diğerlerinin mevcudiyeti ve duyarlılığına bağlıdır. Bağlanma teorisyenlerine benzer şekilde Kohut (1971), tamamen bakım verene bağımlı olunan bebeklik döneminde kurulan ilişkilerin, sağlıklı narsisizmin korunması için özellikle önemli olduğunu vurgular. Benliğin bu erken evresinde, çocuğun benliği olgun değildir ve kendi kendine uyumu sağlamak için bakım verenine güvenir. Gelişimsel süreç boyunca bir kişi bakım verenine daha az bağımlı hale gelse de, bağımlılığın tüm yaşam süreci boyunca sınırlı bir şekilde sürdüğünü vurgular (Kohut 1977). Bu yaklaşım, Bowlby (1988) ve Ainsworth'un (1991) bağlanma ihtiyaçlarının yaşam boyu devam etmesinin önemi konusundaki görüşleri ile paraleldir (Banai ve ark. 2005).

\section{Kendilik nesnesinin depresyon, anksiyete ve öznel iyi oluş ile ilişkisi}

Kohut ve Wolf (1978) erken dönemde aynalama, idealleştirme ve ikizlik alanlarında yaşanan eksikliklerin kendilik bozuklularına yol açtığını savunmaktadır. Örneğin, kişinin kendilik nesnesi ihtiyaçlarının yeterince karşılanmaması, yetişkinlikte bu ihtiyaçlara duyulan açlığı veya bu ihtiyaçlardan kaçınmayı aktive edebilir. Çocuğu yeterince aynalamayan, eksik, ihmalli veya tutarsız bakım verenleri olan bir çocuk, aynalanma açlı̆ğ olan ve özel olma hissini arttırmakiçin başkalarına ihtiyaç duyan bir birey olabilir. Kendilik nesnesinde oluşan eksiklikler, patolojik narsisizm, duyguları düzenleme güçlüğü ve kişiler arası işlevsellikteki bozukluklar gibi çok 
çeşitli psikolojik problemler ile ilişkilendirilmiştir (Kohut 1984). Bununla birlikte, ortaya çıkan psikopatolojinin derecesi ve türü, birincil ihtiyaçların karşılanmadığı gelişim aşamasına bağlıdır (Fonagy ve Target 1997; Kohut ve Wolf 1978). En aşırı durumlarda, ihtiyaç eksikliği çok erken dönemde gerçekleşir ve kendilik nesnelerinin farkında olmanın önüne geçer. Ters uçta, nevrotik örgütlenme bireylerin idealleri için yaşamasını içerir. Ortalama eksiklikler, gerçekçi hırsların veya olgun ego ideallerinin içselleştirilememesine yol açarak, parçalanma korkusu ve eleştiriye, olumsuz duygu ve düşüncelere, yalnızlığa karşı artan savunmasızlığa neden olur (Kohut 1971). Narsistik ve sınır kişilik bozuklukları gibi kişilik bozukluklarının bu kendilik tehditlerinden kaynaklandığ düşünülmektedir. Kohut’a (1977) göre narsisistik kişilik bozukluğu veya davranış bozukluğunun temelinde kendilikte zayıflama yatmaktadır. Narsistik kişilik bozukluğunda aşırı duyarlılık, depresyon hipokondriyazis ve heves kaybı gibi belirtiler görülmektedir. Kendilik nesnesi ile deneyimlerin farklılıklarından kaynaklı olarak, kendilik patolojisi semptomları, yeterince uyarılmamış kendilik, parçalanan kendilik, aşırı uyarılmış kendilik ve aşırı yüklenmiş kendilik olarak dört grupta sınıflandırılmıştır (Kohut ve Wolf 1986).

Erken dönemlerde kendilik nesnelerinin uyarıcı cevapları yeterli olmadığında, yeterince uyarılmamış kendilik ortaya çıkmaktadır. Bu kendilik yapısına sahip bireylerde canlılık eksiktir. Kohut (1977), kendilikte yaşanan yoksunluk deneyimini "boşluk depresyonu" olarak tanımlamaktadır. Morrison (1986) ise, kendilik nesnesinin yetersiz yanıtlarından ötürü hedeflerin, ihtirasların gelişemediğini ve bu sebeple boşluk depresyonunun meydana geldiğini düşünmektedir. Boşluk depresyonu klinik olarak kişinin kendisini ümitsizlik, yoksunluk ve boşluk içinde hissettiği ve algıladığı bir durum olarak tanımlanmaktadır. Benzer şekilde, Banai ve arkadaşlarının (2005) çalışması, Kohut'un (1977, 1984) kendilik nesnesi açlığı ve yetişkinlikteki kendilik nesnesi ihtiyaçlarının duygusal sorunlar ile ilişkili olduğunu öne sürmüştür. Bu bağlamda çalışmalarında psikolojik iyi oluş, depresyon, kaygı ve düşmanlık duygusunun kendiliknesnesi ihtiyaçları ile ilişkisini araştırmışlardır. Sonuç olarak bulguları, Kohut'un (1971) kendilik nesnesi ihtiyaçlarının ve yetişkinlikte bu ihtiyaçların reddedilmesinin duygusal uyumsuzluk ile ilişkili olduğunu desteklemektedir. Sonuçlar ayrıca, aynalama ve ikizlik yoksunluğunun, benlik saygısı, psikolojik iyi oluş, depresyon ve anksiyete ile pozitif ilişkili olduğunu göstermektedir. İdealizasyon ve ikizlikten kaçınma, psikolojik iyi oluş, kaygı, depresyon ve düşmanlık duyguları ile anlamlı olarak ilişkili bulunmuştur (Banai ve ark. 2005).

\section{Bağlanmanın depresyon, anksiyete ve öznel iyi oluş ile ilişkisi}

Birincil bakım verenler ile kurulan ilişkiler sonucu oluşan bağlanma stilleri, bireylerin yetişkinlik dönemindeki psikolojik işlevleri ile ilişkili görünmekte, güvensiz bağlanma ruh sağlığı bozuklukları ile ilişkilendirilmektedir (Mikulincer ve Shaver 2012, Dozier ve ark. 2008). Mikulincer ve Shaver (2012), hem klinik hem de klinik olmayan örneklemlerde yapılan çalışmaları gözden geçirmiş ve güvensiz bağlanmanın bireylerde hafif sıkıntıdan ağır kişilik bozukluklarına ve hatta şizofreniye kadar bir çok farklı ruhsal bozuklukla ilişkili olduğunu bulgulamışlardır. Aynı zamanda, güvenli bağlanma daha az davranışsal 
problemler ile de ilişkili bulunmuştur (Leekers ve ark. 2009). Bunun yanı sıra, güvensiz bağlanma stillerinden biri olan kaçınmacı bağlanma, sıkıntılı durumlarda bakım verenin çocuğun ihtiyacını karşılamamasının bir sonucu olarak yetişkinlik döneminde depresyon ve kaygı gelişimi ile de ilişkili görülmektedir. Bu durum çocuğun olumsuz duygularını ifade etmesinden kaçınmasına ve diğerleri ile yakınlık arayışının en aza indirilmesine yol açabilmektedir (Bradley 2000, Cassidy 1994). Benzer şekilde, güvensiz bağlanmaya sahip olmanın kayg1, depresyon, sosyal izolasyon gibi içselleştirici problemlere bir zemin oluşturduğu düşülmektedir (Brumariu ve Kerns 2010). Madigan ve ark. (2012), güvensiz bağlanmaya sahip çocukların güvenli bağlanmaya sahip çocuklara kıyasla iki kat daha fazla içselleştirici problemlere sahip olduğunu bulgulamışlardır.

Bu durumla paralel olarakyetişkinlik bağlanması öznel iyi oluşüzerindeki bireysel farklılıklara da katkıda bulunabilmektedir. Öznel iyi oluş, en basit deyimiyle her insanın deneyimlediği mutlu olma hali olarak tanımlanmaktadır (Seligman ve Csikszentmihalyi 2000). Öznel iyi oluşun en etkili teorilerinden biri, mutluluk, yaşam doyumu, olumlu duyguların varlığı gibi kavramları içermektedir (Myers ve Diener 1995). Araştırmalar, yetişkin bağlanmasının öznel iyi oluşa katkıda bulunduğunu gösteren ampirik kanıtlar sunmaktadır. Örneğin, yetişkinlikte kaygılı ve kaçınmacı bağlanma öznel iyi oluş ile negatif ilişkili bulunmuş, olumsuz duygulanım ile ise pozitif ilişkili bulunmuştur (Wearden ve ark. 2005).

\section{Duygu düzenlemenin aracı etkisi}

Duyguları düzenleyebilme, daha fazla işlevsel davranışa ulaşılabilirlik ve farklı duygusal durumlarda uygun ve esnek tepkiler verebilmektir (Gross ve Thompson 2007). Öte yandan, duyguları etkin bir biçimde düzenleyememe, daha az işlevsel stratejiye sahip olma, farklı durumlarda uygun kararları verememek ile karakterize edilmekte (Fox 1994, Denham 1998) ayrıca çeşitli psikopatolojik semptomlar ve gelişimsel süreçte yaşanacak sıkıntılar ile ilişkili görülmektedir (Maughan ve Cicchetti 2002). Araştırmalar, bireylerin duygu düzenleme stratejilerini alı̧ılmış bir şekilde kullandıklarını ve bu farklılıkların duygusal deneyim, bilişsel ve sosyal işlevsellik gibi psikolojik uyumun bir çok alanı için sonuçları olduğunu göstermektedir (Gross ve John 2003). Birçok psikolojik rahatsızlığın temelinde duyguları kendi kendine uygun ve esnek bir şekilde düzenleyememenin yattığ1 düşünülmektedir. Benzer şekilde duygu düzenlemedeki sorunlar, psikopatolojk semptomların ve duygusal bozuklukların gelişimi ve sürdürülmesinde önemli bir rol oynamaktadır (Garnefski ve ark. 2002, Velotti ve ark. 2013). Duygu düzenlemedeki güçlüklerin kaygı bozuklukları ve majör depresif bozukluk gibi bir dizi duygusal bozuklukla ilişkili olduğu ileri sürülmektedir (Campbell-Sills ve Barlow 2007, Mennin ve Farach 2007). Araştırmalar, duyguları düzenleme şekillerinin öznel iyi oluş üzerinde de önemli bir etkisi olduğunu göstermektedir (Bryant 2003, Tugade ve Fredrickson 2007, Eisner ve ark. 2009, ). Bununla birlikte, hangi duygu düzenleme stratejilerinin işlevsel hangilerinin ise işlevsel olmadığı büyük oranda yer aldığı bağlama göre değişmektedir. Kapsamlı bir şekilde yapılan araştırmalar bazı duygu düzenleme stratejilerinin durumlar arasında psikolojik iyi oluşu teşvik edeceğini veya azaltacağını göstermektedir. Örneğin; duyguların bastırılması genellikle pozitif duygularda 
(Gross ve Levenson 1997), öznel iyi oluşta (Gross ve John 2003), ve kişilerarası işlevsellikte (Butler ve ark. 2003) düşüşle ilişkilendirilmiştir.

Araştırmalar, güvenli bağlanmanın çocuğun olumlu veya olumsuz duygularının bakım vereni tarafından onaylanması ile geliştiğini ve yetişkinlikteki duygu düzenleme becerisinin temellerini oluşturduğunu savunmaktadır (Siegel 2012, Schore 2015). Güvenli bağlanmanın, bağlanma figürleri güvenli duygusal ve fiziksel ortamı yaratarak çocuğun ihtiyaçlarına sürekli olarak düzenli ve niteklikli bir şekilde cevap verdiğinde oluştuğu düşünülmektedir. Güvenli bağlanmaya sahip çocuklar bakım vereni tehlike anında güvenli bir sı̆̆ınak olarak görürler (Bowlby 1982). Birincil bağlanma stratejileri, bağlanma figürlerine yakınlık arayışını içerir. Yakınlık arayışı karşılanmadığında, hiperaktivasyon veya deaktivasyon stratejileri gibi ikincil stratejiler kullanılır. Bu stratejiler diğerleri ile duygusal mesafeyi artırma (Mikulincer ve ark. 2003) ve üzücü bilişlerin ve anıların bastırılması (Shaver ve Mikulincer 2002) gibi stratejileri içermektedir. Bu streatejiler sıkıntıyı artırabilir çünkü işlevsel olmayan duygu düzenleme stratejileridir (Mikulincer ve Shaver 2007).

Bakım verenlerin ulaşılabilirliği ve duyarlılığına bağlı olarak çocuklar yetişkinlik boyunca da devam eden ve kişilik süreçlerini etkileyen içsel çalışma modelleri geliştirirler (Mikulincer ve Shaver 2007). Güvenli bağlanma stiline sahip bir birey, kendi ile ilgili olumlu inançlarının yanı sıra, başkalarının mevcudiyeti ile ilgili de olumlu inançları içeren bir "içsel çalışma modeli” geliştirir. Araştırmalar, bağlanma ilişkisinin kalitesinin, çocuğun bakım vereni ile ilgili varlığı ve davranışları ile ilgili beklentilerini (içsel çalışma modelleri) etkileyerek duygu düzenlemesini etkilediğini göstermektedir (Bowlby 1969, 1982). Bir başka deyişle, içsel çalışma modellerinin, bireylerin sıkıntılı durumlardayken yaşadıkları bilişsel, duyuşsal ve davranışlar tepkilerini etkileyerek duygu düzenlemeye şekil verdikleri düşünülmektedir.

Bunun yanı sıra, güvenli bağlanmayı sağlayan ebeveynler, çocukların duygularını ve bu duygulara sebep olan etmenleri daha doğru ve içgörüsel olarak değerlendirebilir ve daha etkili bir yardım sağlayabilirler. Daha sonra çocuk ile sıkıntılı deneyimleri üzerine hassas bir yaklaşım ile konuşabilir, bu sıkıntılı durumu yönetmek için yararlı stratejiler hakkında daha fazla bilgi sunabilirler. Güvenli bağlanma, olumsuz duyguların reddedilmesi anlamına gelmemektedir. Aksine, etkin duygu düzenleme, olumlu ve olumsuz duyguları entegre etme esnekliği, ve bakım verenin yokluğunda bile rahatsız edici durumları deneyimleme ve tolere etme yeteniğinin artmasıdır (Bowlby 1969, 1980, Cassidy 2008). Sıkıntılı durumlarda güvenli bağlanan çocuk tarafindan uygulanan duygu düzenleme stratejileri, bakım verene karşı açık, doğrudan ve aktif ifadeleri içerir. Deneyimin sonunda birlikte yaşanacak olumlu ifadeler, ilişkiye olan ilgiyi korumaya hizmet eder (Bowlby 1982, Bretherton 1990). Örneğin, duygusal olarak erişilebilir ve duyarlı diğerleri ile etkileşimler, çocuğun duyguların gösterilmesinin ve onaylanmasının duygusal dengeyi sağlamak için bir adım olduğunu anlamasını ve bir kişinin duygularını araştırmanın ve anlamaya çalışmanın sosyal olarak kabul edilebilir ve yararlı oluğunu öğrenmesini sağlar (Cassidy 1994). Bu nedenle, güvenli bağlanmaya sahip bireyler, bakım verenleri ile daha önceden deneyimledikleri duygu düzenleme konusundaki olumlu deneyimlerinin 1şı̆̆ında sıkıntıyı yönetmelerini sağlayan uyarlanabilir duygu düzenleme stratejilerini öğrenirler. Güvenli bağlanan bireylerin aksine, 
kaçınmacı bağlanan bireyler düşünceleri ve duygularının gizlemeyi tercih ederler. Rahat gözükme eğiliminde olsalar da bastırdıkları çözümlenmemiş sıkıntıları, yaşamın kaçınılmaz olumsuzlukları ile başa çıkma yeteneklerini köreltir. Bu bozulma, özellikle bir problemle aktif başa çıkmayı ve dış destek kaynaklarına başvurmayı gerektiren uzun süreli, zorlu stresli deneyimler sirasinda olasıdır (Berant ve ark. 2008).

Kendilik nesnesi teorisine göre ise, yaşamlarının erken döneminde bebeğin duygu düzenlemesi tamamen birincil bakım verenidir (kendilik nesnesi). Birincil bakım veren genellikle annedir, süreç içinde baba ve diğer kişiler de kendiliknesnesi olmaya başlar. Kendilik nesnesi, gelişim süreci boyunca çevreye uyum sağlamanın, dürtü düzenlemesinin ve bütünleştirmesinin temelidir. Benliğin gelişim süreci, erken dönemlerde bakım veren ile yaşanan deneyimler sonucu, anne tarafindan gerçekleştirilen duygu düzenlemenin, kendi kendine yapılabilir hale gelme sürecidir. Bakım veren ve çocuk arasındaki ilişkinin kalitesine bağlı olarak gerçekleşen karşılıklı duygusal geçişler duygusal farkındalığın gelişmesi için önemlidir. Çocuk, kendi duygularının yansımalarını annesinde görür, bu sayede anne çocuğun kendi duygularını deneyimleyebilmesi için duygusal bir ayna işlevi görür. $\mathrm{Bu}$ ilişkide, kopmalar ve yeniden birleşmeler meydana geldikçe çocukta güven duygusu ve empati gelişimi desteklenir. Bu bağlamda, benlik gelişimi duygu düzenlmesinin kazanılması ve artmasıdır (Schore 2003). Kendilik psikolojisine göre benlik bütünüğünün temel işlevi duygusal düzenlemeyi sağlayabilmektir. Öncelikle birincil bakım verenin (genellikle anne) ve sonrasında bakım veren diğerlerinin (baba ve diğer önemli kişiler) uyumlu ve empatik olmayan tutumları, gelişim süreci içerisinde duygu düzenlemenin öğrenilememesine ve bu sebeple depresyon, kaygı bozuklukları, kişilik bozuklukları gibi psikolojik rahatsızlıkların oluşumuna sebep olabilmektedir (Kohut 1977).

\section{Sonuç}

Gözden geçirilen çalışmalara bakıldığında kendilik nesnesi ve bağlanma kavramlarının birlikte ele alındığı sınırlı çalışma olduğu görülmektedir (Banai ve ark. 2005, Lopez ve ark. 2013). Her iki teori de, erken bakım ilişkisini ve bunun sağlıklı bir kendilik duygusunun gelişimi üzerinde önemli bir etkisi olduğunu vurgulamaktadır. Bu araştırmada, kendilik nesnesi ve bağlanma boyutlarının olası etkilerini incelemek için bağlanma ve kendilik nesnesi ile depresyon, anksiyete ve öznel iyi oluş ilişkisine dair literatür bulguları araştırılmıştır. Bowbly'nin bağlanma teorisi, bağlanma ilişkisinde duygu düzenleme stratejilerine (hiperaktivasyon ve deaktivasyon) odaklanmıştır (Cassidy 1994). Benzer şekilde, kendilik psikolojisinde de duygu düzenlemenin önemli bir yeri olduğu görülmektedir. Kohut’a göre benliğin gelişim süreci, erken dönemlerde bakım veren ile yaşanan deneyimler sonucu anne (kendilik nesnesi) tarafından gerçekleştirilen duygu düzenlemenin, kendi kendine yapılabilir hale gelme sürecidir (Schore 2003). Bu bağlamda, mevcut ilişkilerde duygu düzenlemenin olası aracılık etkisi de incelenmiştir.

Mevcut bulgular, kendilik nesnesi ihtiyaçlarının karşılanmaması durumunda depresyon ve kaygının artabileceği, öznel iyi oluşun ise azalacağı yönündedir (Banai ve ark.2005). Kohut'un kendilik nesnesi açlı̆̆1 ve yetişkinlikteki kendilik nesnesi ihtiyaçlarının duygusal sorunlar ile 
ilişkili olduğunu öne sürmesine rağmen araştırmalar daha çok kendilik nesnesinin narsisizm ve borderline kişilik bozukluğu ile ilişkisine bakmıştır (Tonkin ve Fine 1985, Masterson 1993). İleride yapılacak araştırmaların depresyon, kaygı bozuklukları gibi farklı psikolojik bozuklukları değerlendirmesinin önemli olacağı düşünülmektedir. Bu alanda elde edilecek bulgular klinik temelli psikanalitik bir teoriyle, klinik alanda çalışan psikologlar tarafindan yürütülen ampirik çalışmaların entegresyonunun elde edilmesini de sağlayacaktır. Daha fazla veri elde edilmesinin klinik öngörüleri geliştirebileceği ve Kohut'un teorilerini daha işlevsel kılabileceği düşünülmektedir.

Kendilik psikolojisi teorisinde, kendilik nesnesinin duygu düzenleme ile doğrudan ilişkili olduğu görülmektedir. Birincil bakım veren tarafından kendilik nesnesi ihtiyaçlarının karşılanmaması ve empatik olmayan tutumları gelişim süreci içerisinde duygu düzenlemenin öğrenilememesine ve bunun bir sonucu olarak depresyon, kaygı bozuklukları, kişilik bozuklukları gibi psikolojik rahatsızlıkların oluşumuna sebep olabileceğini göstermektedir (Kohut 1977). Sonuçlar, kendilik nesnesi ve psikolojik belirtiler araştırılırken duygu düzenlemenin aracı etkisinin incelenmesinin önemli olabileceği yönündedir. Bu alanda yapılacak daha fazla araştırmaya gereksinim duyulmaktadır.

Benzer şekilde, bağlanma boyutlarından olan kaçınmacı ve kaygılı bağlanmanın depresyon ve kaygının artması, öznel iyi oluşun ise azalması ile ilişkili olduğu görülmektedir (Seligman ve Csikszentmihalyi 2000, Dozier ve ark. 2008, Mikulincer ve Shaver 2012). Araştırmalar, bağlanma ile psikolojik semptomlar arasında duygu düzenlemenin etkisi olabileceği yönündedir. Güvensiz bağlanmaya sahip bireyler erken çocukluk döneminde sıkıntı ile nasıl baş edeceklerini ve etkin duygu düzenleme stratejilerini kullanmayı öğrenememekte ve bu durum psikolojik sıkıntıların artmasına ve öznel iyi oluşun azalmasına sebep olabilmektedir (Siegel 2012, Schore 2015). Bu durum, klinik uygulamada öznel iyi oluş veya psikolojik sağlık üzerine yapılacak çalışmalarda duygu düzenlemenin hedef alınmasının önemli olabileceğini düşündürmektedir.

\section{Kaynaklar}

Ainsworth MD, Blehar M, Waters E, Wall S (1978) Patterns of Attachment: A Psychological Study of the Strange Situation. New York, NY, Psychology Press.

Banai E, Mikulincer M, Shaver PR (2005) "Self object" needs in kohut's self psychology: links with attachment, self-cohesion, affect regulation, and adjustment. Psychoanal Psychol, 22:224-260.

Berant E, Mikulincer M, Shaver PR (2008) Mothers'attachment style, their mental health, and their children's emotional vulnerabilities: A 7-year study of children with congenital heart disease. J Pers, 76:31-66.

Bowlby J (1969) Attachment and Loss v. 3 (Vol. 1). New York, NY, Random House.

Furman W, Buhrmester D (2009) Methods and measures: The network of relationships inventory: Behavioral systems version. Int J Behav Dev, 33:470-478.

Bowlby J (1982) Attachment and loss: retrospect and prospect. Am J Orthopsychiatry, 52:664-678.

Bowlby J (1988) Developmental psychiatry comes of age. Am J Psychiatry, 145:1-10

Bradley S (2000) Affect Regulation and the Development of Psychopathology. New York, Guilford Press.

Brennan KA, Clark CL, Shaver PR (1998) Self-report measurement of adult attachment: An integrative overview. In Attachment Theory 
and Close Relationships (Eds JA Simpson, WS Rholes):46-76. New York, Guilford Press.

Bretherton I, Ridgeway D, Cassidy J. (1990). Assessing internal working models of the attachment relationship: An attachment story completion task for 3-year-olds. In The John D. and Catherine T. MacArthur Foundation series on mental health and development. Attachment in the Preschool Years: Theory, research, and intervention (Eds MT Greenberg, D Cicchetti, EM Cummings):273-308. Chicago, University of Chicago Press.

Brumariu LE, Kerns KA (2010) Parent-child attachment and internalizing symptoms in childhood and adolescence: A review of empirical findings and future directions. Dev Psychopathol, 22:177-203.

Bryant $F$ (2003) Savoring Beliefs Inventory (SBI): A scale for measuring beliefs about savouring. J Ment Health, 12:175-196.

Butler EA, Egloff B, Wlhelm FH, Smith NC, Erickson EA, Gross JJ (2003) The social consequences of expressive suppression. Emotion, 3:48-67.

Campbell-Sills L, Barlow DH (2007) Incorporating emotion regulation into conceptualizations and treatments of anxiety and mood disorders. In Handbook of Emotion Regulation (Ed JJ Gross):542-559. New York, Guilford Press.

Cassidy J (1994) Emotion regulation: Influences of attachment relationships. Monogr Soc Res Child Dev, 59:228-249.

Cassidy J (2008). The nature of the child's ties. In Handbook of Attachment: Theory, Research, and Clinical Applications (Eds J Cassidy, PR Shaver):3-22. New York, Guilford Press.

Denham SA (1998) Emotional Development in Young Children. New York, Guilford Press.

Dozier M, Stovall-McClough KC, Albus KE (2008) Attachment and psychopathology in adulthood. In Handbook of Attachment: Theory, Research, and Clinical Applications (Eds J Cassidy, PR Shaver):718-744. New York, Guilford Press.

Eisner LR, Johnson SL, Carver CS (2009) Positive affect regulation in anxiety disorders. J Anxiety Disord, 23:645-649.

Fonagy P, Target M (1997) Attachment and reflective function: Their role in self-organization. Dev Psychopathol, 9:679-700.

Fox NA (1994) Dynamic cerebral processes underlying emotion regulation. Monogr Soc Res in Child Dev, 59:152-166.

Freud S (1933) New Introductory Lectures on Psychoanalysis. New York, Norton.

Garnefski N, Kraaij V, Spinhoven P (2002) Manual for the Use of the Cognitive Emotion Regulation Questionnaire. Leiderdorp, Netherlands, DATEC.

Gross JJ, John OP (2003) Individual differences in two emotion regulation processes: implications for affect, relationships, and wellbeing. J Pers Soc Psychol, 85:348-362.

Gross JJ, Levenson RW (1997) Hiding feelings: the acute effects of inhibiting negative and positive emotion. J Abnorm Psychol, 106: 95-103.

Gross JJ, Thompson RA (2007). Emotion regulation: conceptual foundations. In Handbook of Emotion Regulation (Ed JJ Gross):3-24. New York, Guilford Press.

Hazan C, Shaver P (1987) Romantic love conceptualized as an attachment process. J Pers Soc Psychol, 52:511-524.

Kohut H (1971) The Analysis of the Self. New York, International Universities Press.

Kohut H (1977) The Restoration of the Self. New York, International Universities Press.

Kohut H (1984) How does Analysis Cure? Chicago, University of Chicago Press.

Kohut H, Wolf E (1978) The disorders of the self and their treatment: An outline. Int J Psychoanal, 59:413-425.

Leerkes EM, Blankson AN, $0^{\prime}$ Brien M (2009) Differential effects of maternal sensitivity to infant distress and nondistress on socialemotional functioning. Child Dev, 80:762-775.

Lopez FG, Siffert KJ, Thorne B, Schoenecker S, Castleberr E, Chaliman R (2013) Probing the relationship between selfobject needs and adult attachment orientations. Psychoanal Psychol, 30:247-263.

Madigan S, Atkinson L, Laurin K, Benoit D (2013) Attachment and internalizing behavior in early childhood: A meta-analysis. Dev Psychol, 49:672-689.

Masterson JF (1993) The emerging self: A developmental, self, and object relations approach to the treatment of the closet narcissistic disorder of the self. Philadelphia, PA, Brunner Mazel.

Mikulincer M, Shaver PR (2012) An attachment perspective on psychopathology. World Psychiatry, 11:11-15.

Maughan A, Cicchetti D (2002) Impact of child maltreatment and interadult violence on children's emotion regulation abilities and 
socioemotional adjustment. Child Dev, 73:1525-1542.

Mennin D, Farach F (2007) Emotion and evolving treatments for adult psychopathology. Clin Psychol, 14:329-352.

Mikulincer M, Shaver PR, Pereg D (2003) Attachment theory and affect regulation: The dynamics, development, and cognitive consequences of attachment-related strategies. Motiv Emot, 27:77-102.

Mikulincer M, Shaver PR (2007) Boosting attachment security to promote mental health, prosocial values, and inter-group tolerance. Psychol Inq, 18:139-156.

Mollon P (2001) Releasing the Self: The Healing Legacy of Heinz Kohut. Philadelphia, PA, Whurr.

Morrison AP (1986) Essential Papers on Narcissism. New York, New York University Press.

Myers DG, Diener E (1995) Who is happy? Psychol Sci, 6:10-19.

Schore AN (2003) Affect Regulation and the Repair of the Self. New York, WW Norton.

Seligman ME, Csikszentmihalyi M (2000) Positive psychology: An introduction. Am Psychol, 55:5-14.

Shaver PR, Mikulincer M (2002) Attachment-related psychodynamics. Attach Hum Dev, 4:133-161.

Siegel D (2012) The Developing Mind: How Relationships and The Brain Interact to Shape Who We Are. New York, Guilford Press.

Strozier CB (2001) Heinz Kohut: The Making of a Psychoanalyst. New York, Farrar, Straus and Giroux.

Schore AN (2002) The neurobiology of attachment and early personality organization. J Prenat Perinat Psychol Health, 16:249-264.

Tonkin M, Fine HJ (1985) Narcissism and borderline states: Kernberg, Kohut, and psychotherapy. Psychoanal Psychol, 2:221-239.

Tugade MM, Fredrickson BL (2007) Regulation of positive emotions: Emotion regulation strategies that promote resilience. J Happiness Stud, 8:311-333.

Velotti P, Di Folco S, Cesare Zavattini G (2013) What we know about "attachment disorders" in childhood. Journal of Special Education and Rehabilitation, 14(3-4):61-77.

Wearden AJ, Lamberton N, Crook N, Walsh V (2005) Adult attachment, alexithymia, and symptom reporting: An extension to the four category model of attachment. J Psychosom Res, 58:279-288.

Wolf E (1988) Treating the Self. New York, Guilford Press.

Yazarların Katkıları: Yazar çalışmaya önemli bir bilimsel katkı sağladığını ve makalenin hazıılanmasında veya gözden geçirilmesinde yardımcı olduğunu kabul etmiştir.

Danışman Değerlendirmesi: Dış bağımsız.

Çıkar Çatışması: Yazar çıkar çatışması bildirmemiştir.

Finansal Destek: Yazar bu çalışma için finansal destek almadığını beyan etmiştir.

Authors Contributions: The author attest that she has made an important scientific contribution to the study and has assisted with the drafting or revising of the manuscript.

Peer-review: Externally peer-reviewed.

Conflict of Interest: No conflict of interest was declared by the author.

Financial Disclosure: The author declared that this study has received no financial support. 